\title{
Subcuticular sutures versus staples for skin closure after primary hip arthroplasty
}

\author{
Hany Elbardesy, Rehan Gul, Shane Guerin
}

From the Department of trauma and orthopaedic, Cork University Hospital, Cork, Ireland

High-quality and cost-effective health care are highly recommended especially in joint replacement surgeries, particularly in total hip arthroplasty. Therefore, it is indispensable for orthopaedic surgeons to spot the potential areas of quality improvement. Evaluating the efficacy of the different ways of skin closure is an unacknowledged topic.

We performed this study following both the Preferred Reporting Items for Systematic Reviews and Metaanalyses Statement (PRISMA) and the Cochrane Handbook for systematic reviews and meta-analysis. Articles were from any country, written in any language. We included all randomised control trials and retrospective cohort studies undergoing primary total hip arthroplasty who either received staples or subcuticular sutures for skin closure. The primary outcome was the incidence of wound infection. Secondary outcomes included length of stay (LOS), time to skin closure, total cost, and patient's satisfaction.

We included five studies in our cumulative metaanalysis. We conducted them using Review Manager V.5.0. We computed the risk ratio as a measure of the treatment effect, taking into account heterogeneity. We used Random-effect models. Primary skin closure with subcuticular sutures had insignificant marginal advantages for wound infections, LOS, and wound oozing. On the contrary, staples were more costeffective and had less time for closure with higher patient's satisfaction.

Except for closure time and patient satisfaction, no significant difference between the two groups. The use of staples after THA may have several slight clinical advantages over the subcuticular sutures.

Funding : This research received no specific grant from any funding agency in the public, commercial or not-for-profit sectors.

Conflict of interest : None declared.
However, owing to the complexities associated with wound closure, future clinical and laboratory studies assessing their complication outlines must be examined before an optimum technique can be determined.

Keywords : total hip arthroplasty; total joint arthroplasty; skin closure ; meta-analysis.

\section{INTRODUCTION}

High-quality and cost-effective health care are highly recommended especially in joint replacement surgeries, particularly in total hip arthroplasty (THA) (1,2). after the application of new health policies, including Comprehensive Care for Joint Replacement (CJR) and Medicare's Bundled Payment Care Initiatives (BPCI), efforts have been directed toward enhancing the qualityrelated outcomes and decreasing the costs $(3,4)$.

Hany Elbardesy, MSc, MRCS, FRCS eng, FEBOT, SICOT Diploma

- Rehan Gul, FRCS, Consultant of trauma and Orthopaedic

- Shane Guerin, FRCS, Consultant of trauma and Orthopaedic Department of trauma and orthopaedic, Cork University Hospital, Cork, Ireland.

Correspondence : Hany ELBARDESY, Cork University Hospital, Cork, Ireland. Phone : +353892106657, $+353214347890$

ORCID ID : https : //orcid.org/0000-0001-8600-6339

Email : hany.elbardesy@ucdconnect.ie

- 2021, Acta Orthopædica Belgica.

Acta Orthopædica Belgica, Vol. 87 - 1 - 2021 
So it is indispensable for orthopaedic surgeons to spot the potential areas of quality improvement (5). Evaluating the efficacy of the different ways of skin closure is an unacknowledged topic. Surprisingly the complications of the surgical wound have shown to extend hospital length of stay (LOS), readmission rates, and health care costs (5-8). The aim of skin closure is rapid skin healing and an acceptable cosmetic appearance while minimising the risk of infection or dehiscence (9). Staples and sutures are the most common way of skin closure after joint arthroplasty (9-11). Skin staples are easy to use and speedway of closure (12). subcuticular skin closure has more cosmetic outcomes (13). Recently, several meta-analyses and systematic reviews have assessed the perioperative outcomes of different wound closure techniques used in orthopaedic procedures. But no published studies comparatively evaluating wound complications and perioperative details between patients whose skin incisions were closed with staples or sutures after THA. The present study aims to use meta-analysis techniques to evaluate complications associated with subcuticular sutures and staples for skin closures after THA. Besides, a systematic approach will be taken to comparatively evaluate variables including infection rate, operative time, length of stay time to wound closure, wound oozing, associated costs, and cosmetic assessments after THA.

\section{MATERIALS AND METHODS}

We performed this study following both the Preferred Reporting Items for Systematic Reviews and Meta-analyses Statement (PRISMA) and the Cochrane Handbook for systematic reviews and meta-analysis(14). We conducted an initial search using the MEDLINE-OVID, Web of Science, PubMed, EMBASE-OVID, Google schooler and Cochrane Library. Grey and unpublished literature were also explored by searching: Grey Matters BIOSIS Previews, International Clinical Trial Registry, ClinicalTrials.gov, UK Clinical Trials Gateway, Networked Digital Library of Theses and Dissertations, UK Clinical Research Network Study Portfolio, Open Grey and Grey Literature Report. We used the following keywords and their combinations : staples, suture, barbed, arthroplasty, hip, wound, closure, and skin. Articles published up to May 2020 were included in our literature search and were limited to studies in human subjects published in any language. Additionally, we crossreferenced the bibliographies of retrieved articles and review papers to ensure that we captured all relevant studies. The quality of the evidence was classified using the US Preventive Services Task Force system for ranking the level of evidence (15).

We included all full-text randomised controlled trials (RCTs) and high-quality observational cohort studies that evaluate skin closure using Subcuticular sutures or staples, regardless of the depth of the subcutaneous tissue. We excluded all studies that did not meet one or more of the eligibility criteria.

Two authors (HE and RG) independently screened all titles and abstracts identified by the initial search to assess their eligibility for inclusion. Then we did a full screening of the manuscript and conducted a final evaluation of a study's eligibility. After all eligible manuscripts had been evaluated for inclusion, data extraction was conducted by the same two reviewers. Any discrepancies with collected data were resolved by consensus between the two reviewers. Outcome Measures The primary outcome measures evaluated in our meta-analysis was the incidence of wound infection. The secondary outcomes were length of stay, wound oozing, time to skin closure, total cost and patient's satisfaction (16).

We conducted a statistical analysis by using Review Manager (RevMan), version 5.3 (The Nordic Cochrane Centre, The Cochrane Collaboration, 2009, Copenhagen, Denmark) (17). Heterogeneity between studies was evaluated using the $\mathrm{I}^{2}$ statistic and $\mathrm{a} \mathrm{c}^{2}$ of $<0.05$ was used to determine the significance of the heterogeneity between studies (14). Risk ratios (RRs) were reported for dichotomous variables such as wound complications, whereas mean differences and standard deviations (SDs) were used for continuous variables. All analyses were conducted using the Mantel-Haenszel randomeffects model. The results of our meta-analysis were then illustrated using forest plots, which used a 95\% confidence interval (CI) for each study and a cumulative weighted mean differences (MD) for 
all the studies involved. Besides, variables which were inconsistently reported were investigated in the systematic review portion of this study (14).

\section{RESULTS}

Our literature search revealed 1522 unique references. After reviewing the titles and abstracts

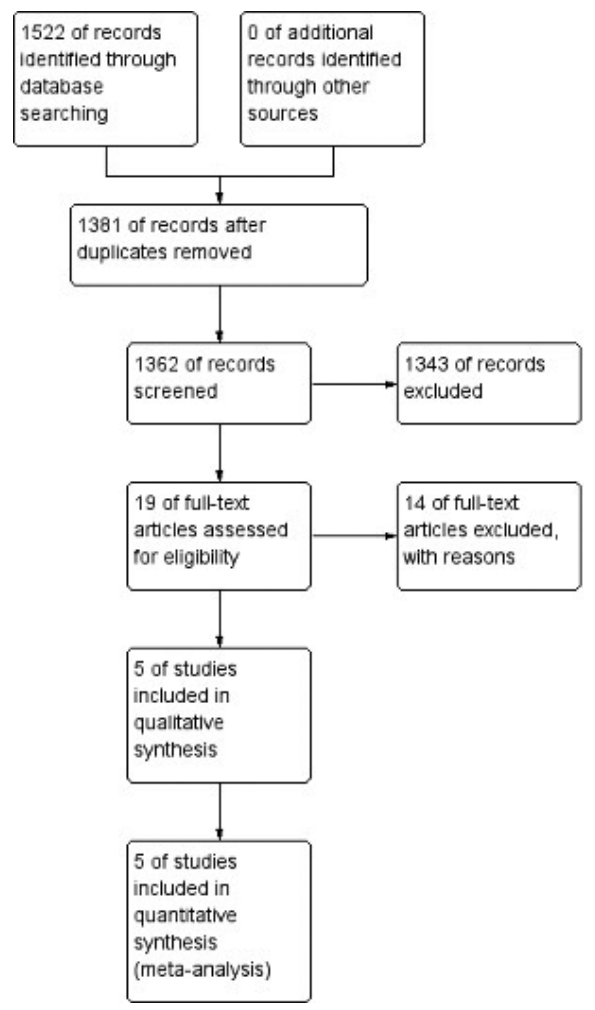

Figure 1. - Preferred reporting items for systematic reviews and meta-analyses (PRISMA) flow chart. of all studies, five studies were eligible for both quantitative and qualitative analysis, 4 RCTs (level I evidence), and one high-quality retrospective cohort study (level II evidence). The five selected studies included 497 hips, of which, 247 were closed using Subcuticular sutures and 250 using staples (fig 1). A summary of the patient's demographics is presented in (Table 1). Noteworthy, the study by Khan et al. (18), he included three comparative techniques of skin closure in his study, one was subcuticular sutures (included), the second was interrupted sutures (excluded), and the third was staples (included). Additionally, two studies $(18,19)$ included results from both knee and hip arthroplasty, we only included the results of the hip arthroplasty.

The subjects in the subcuticular sutures had an average age of 69.47 years (range, 41.0-90.0 years), of which 97 of 225 patients (43.11\%) were male, with an average body mass index of 28.2 $\mathrm{kg} / \mathrm{m} 2$ (range : 15.9-46 kg/m2). The staple cohort had a similar patient distribution with an average age of 69.07 years (range : 33-86 years), of which $97 / 223(43.49 \%)$ were male, with an average body mass index of $28.53 \mathrm{~kg} / \mathrm{m} 2$ (range, $17.6-38.9 \mathrm{~kg}$ ) $\mathrm{m} 2$; Table 1). Additionally, the average incision length in the sutures and staple cohort was $12.4 \mathrm{~cm}$ (range, 7-23 cm) and $12.15 \mathrm{~cm}$ (range, 7.5-22 cm), respectively.

We assessed the risk of bias for all included studies by using the Cochrane risk of bias criteria (Fig 2 and 3) (14).

Our meta-analysis comparatively assessed the efficiency of subcuticular sutures and staples as it

Table 1. - Patient's demographics

\begin{tabular}{|c|c|c|c|c|c|c|c|c|}
\hline \multirow[t]{2}{*}{ Study } & \multirow[t]{2}{*}{$\begin{array}{l}\text { Study } \\
\text { type }\end{array}$} & \multirow{2}{*}{$\begin{array}{c}\begin{array}{c}\text { Number of } \\
\text { patients }\end{array} \\
\text { (suture/Stables) }\end{array}$} & \multicolumn{2}{|c|}{ BMI } & \multicolumn{2}{|c|}{$\begin{array}{c}\text { Gender(Male/ } \\
\text { Female) }\end{array}$} & \multicolumn{2}{|c|}{ Age } \\
\hline & & & MDB & Staples & MDB & Staples & MDB & Staples \\
\hline $\begin{array}{l}\text { Glennie et } \\
\text { al. } 2017\end{array}$ & RCT & $72 / 68$ & $29.4 \pm 5.6$ & $30.51 \pm 6.6$ & $35 / 37$ & $32 / 36$ & $66.7 \pm 10.7$ & $68.7 \pm 10.9$ \\
\hline $\begin{array}{l}\text { Khan et al. } \\
2006\end{array}$ & RCT & $33 / 36$ & $\begin{array}{c}27.4(15.9 \text { to } \\
37.9)\end{array}$ & $\begin{array}{c}26.9 \text { (21.1 to } \\
38.9)\end{array}$ & $13 / 20$ & $20 / 16$ & $71(44$ to 90$)$ & 71 (33 to 83$)$ \\
\hline $\begin{array}{l}\text { Livesey et } \\
\text { al. } 2009\end{array}$ & RCT & $38 / 39$ & $29.2(20$ to 46$)$ & $29.6(22$ to 40$)$ & $13 / 25$ & $13 / 26$ & 71.4 (41 to 87 ) & $68.2(48$ to 86$)$ \\
\hline $\begin{array}{l}\text { Roumeliotis } \\
\text { et al. } 2019\end{array}$ & RCS & $22 / 24$ & NA & NA & NA & NA & NA & NA \\
\hline $\begin{array}{l}\text { Rui et al. } \\
2017\end{array}$ & RCT & $82 / 83$ & $\begin{array}{c}26.8 \\
(16.4-32.2)\end{array}$ & $\begin{array}{c}27.1 \\
(17.6-33.4)\end{array}$ & $36 / 46$ & $39 / 44$ & NA & NA \\
\hline
\end{tabular}




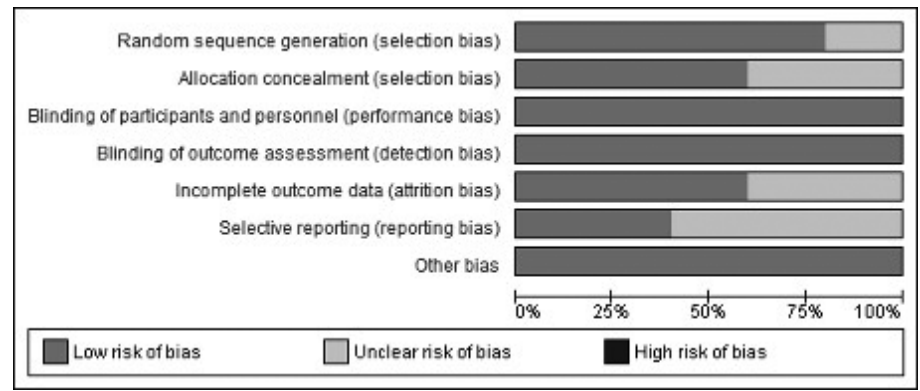

Figure 2. - Risk of bias graph : review authors' judgements about each risk of bias item presented as percentages across all included studies.

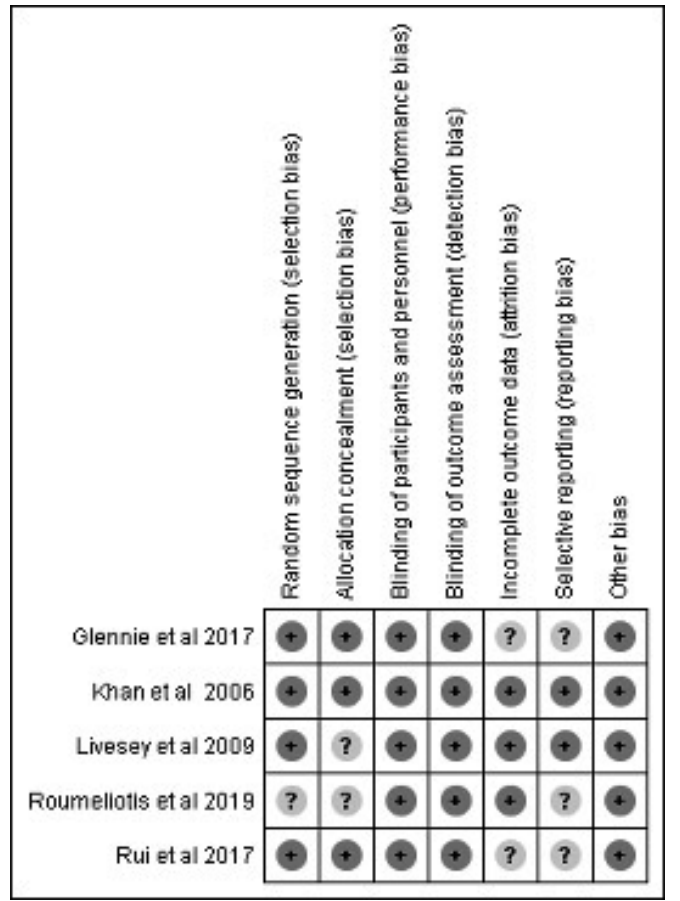

Figure 3. - Risk of bias summary : review authors' judgements about each risk of bias item for each included study.

correlates to five postoperative outcomes: wound infection, length of stay, time to skin closure, total cost, patient's satisfaction.
Overall, four studies indicating 469 hips reported on postoperative wound infections. Of the 225 hips closed with sutures, 4 wound infections were reported, whereas seven events were noted in the 244 THAs closed with staples. Heterogeneity analysis demonstrated no statistical evidence for heterogeneity $\left(\mathrm{I}^{2=} 0 \%\right)$. Although wound infection rates among patients primarily closed with sutures and staples favoured sutures, the results were insignificant (RR, $0.70 ; 95 \%$ CI, 0.21-2.29; $\mathrm{P}=0.83$; Fig. 4). Funnel plot comparison is demonstrated in (fig 5).

Four studies reported the average length LOS after primary THA representing a total of 438 hips. There one study (20), showed double the LOS in days for the skin group $(n=12)$ in comparison to the sutures group $(n=6)$. Qualitatively, there is no noticeable difference among patients who receive staples or sutures. Heterogeneity analysis demonstrated high statistical evidence for variation within the study $\left(\mathrm{I}^{2}=99 \%\right)$. Although LOS rates were less among patients primarily closed with sutures , $(\mathrm{MD}=1.69)$, our data were not statistically significant (95\% CI, 2.01-5.39; $\mathrm{P}<0.001$; Fig 6).

Four studies reported on prolonged wound oozing encompassing a total of 350 hips. Twenty events

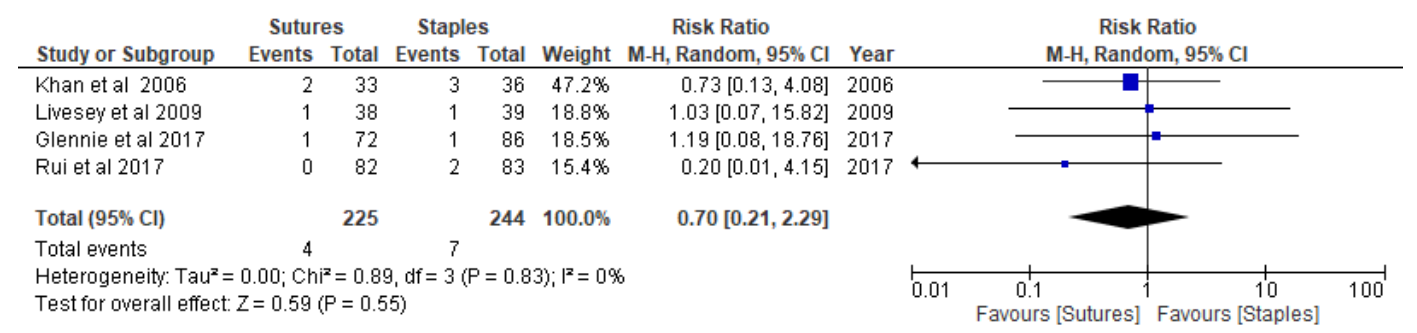

Figure 4. - Forest plot of comparison : 1 Monocryl and derma bond vs staples in total hip arthroplasty, outcome : Infection. 


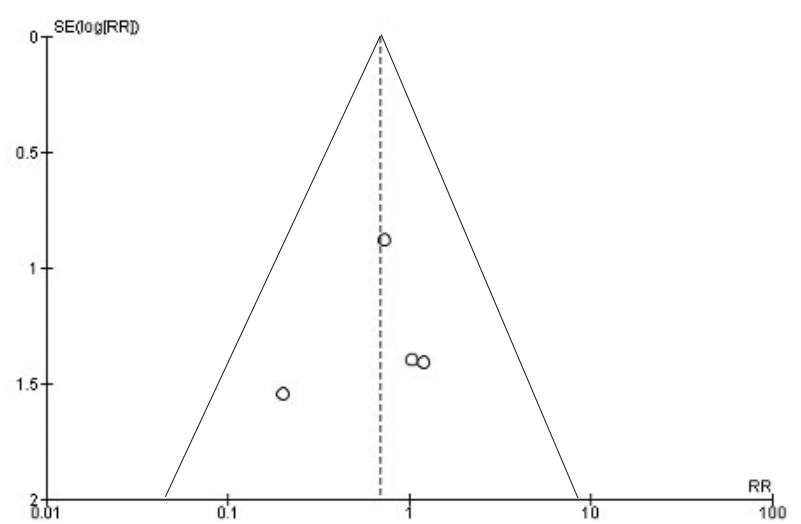

Figure 5. - Funnel plot of comparison : 1 Monocryl and derma bond vs staples in total hip arthroplasty, outcome : 1.5 Infection.

were reported of the 165 hips in the suture plus skin glue cohort, and 47 events were cited of the
185 hips receiving staples. Heterogeneity analysis demonstrated mild statistical evidence for variation within the study $\left(\mathrm{I}^{2}=70 \%\right)$. Although insignificant, data pooled by random-effects model suggested a lower risk of prolonged wound drainage among the suture cohort (RR, $0.38 ; 95 \% \mathrm{CI}, 0.10-1.36 ; \mathrm{P}=$ 0.02 ; Fig 7).

Four studies reported on prolonged wound oozing involving a total of 469 hips. All of them reported significant less time consumption with the staples cohort. Heterogeneity analysis demonstrated high statistical evidence for variation within the study $\left(\mathrm{I}^{2}=100 \%\right)$. The cumulative $\mathrm{MD}$ was significant 152.80 (95\% CI, 22.11-327.72; P $<0.001$; Fig 8).

Four studies reported on total cost for skin closure encompassing a total of 446 hips. All of them reported significant less cost with the staples cohort. Heterogeneity analysis demonstrated high

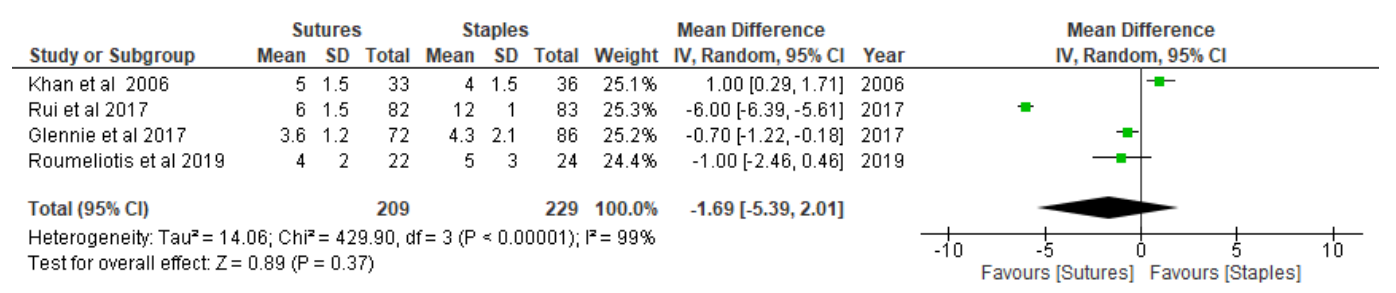

Figure 6. - Forest plot of comparison : 1 Monocryl and derma bond vs staples in total hip arthroplasty, outcome : Length of stay.

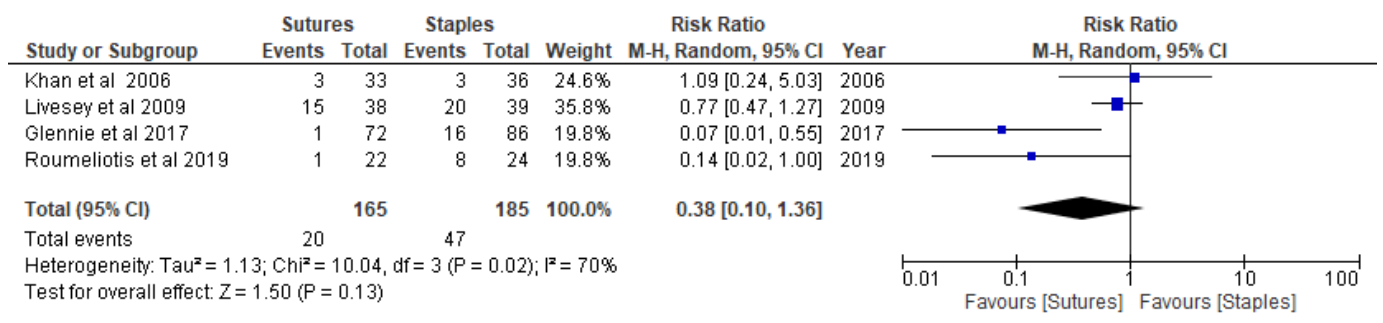

Figure 7. - Forest plot of comparison : 1 Monocryl and derma bond vs staples in total hip arthroplasty, outcome : Wound oozing.

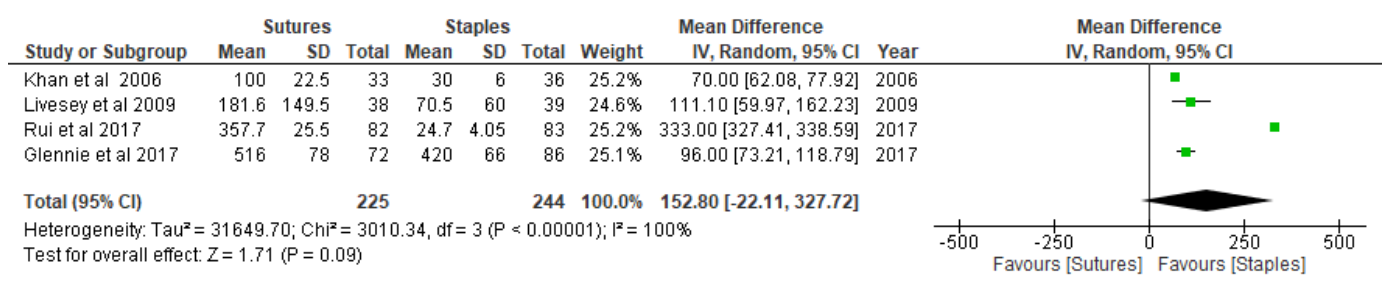

Figure 8. - Forest plot of comparison : 1 Monocryl and derma bond vs staples in total hip arthroplasty, outcome : Time for closure. 


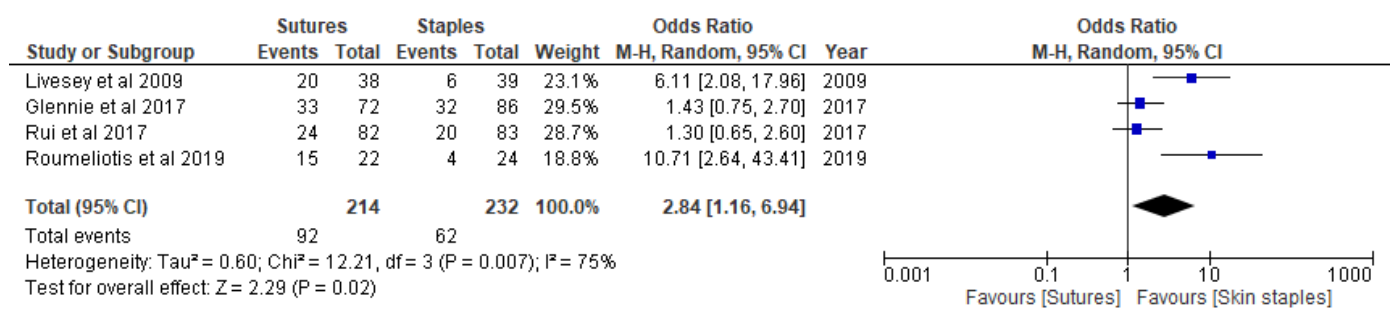

Figure 9. - Forest plot of comparison : 1 Monocryl and derma bond vs staples in total hip arthroplasty, outcome : Total cost.

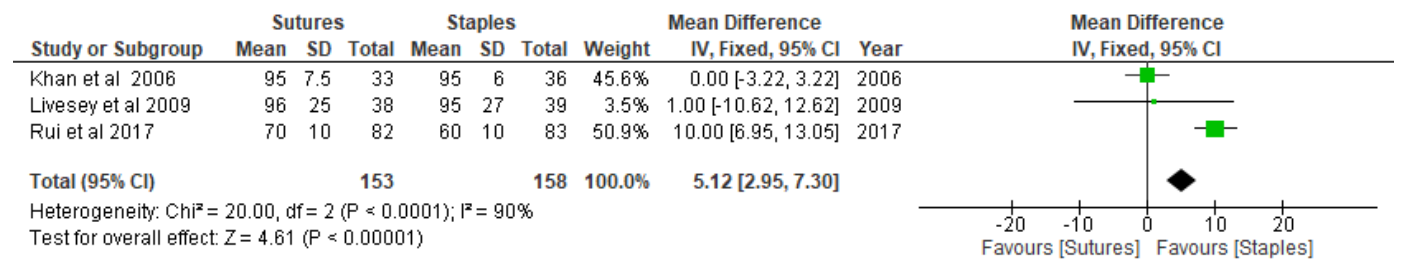

Figure 10. - Forest plot of comparison : 1 Monocryl and derma bond vs staples in total hip arthroplasty, outcome : 1.7 Patients satisfaction.

statistical evidence for variation within the study $\left(\mathrm{I}^{2}\right.$ $=75 \%)$. The odd ratio was significant $2.84(95 \% \mathrm{CI}$, 1.16-6.94; $\mathrm{P}<0.05$; Fig. 9).

Three studies reported on patient's satisfaction including a total of 311 hips. they reported significant more patient's satisfaction with the staples group. Heterogeneity analysis demonstrated high statistical evidence for variation within the study $\left(\mathrm{I}^{2}=90 \%\right)$. The cumulative MD was significant 4.12 (95\% CI, 4.01-12.25; $\mathrm{P}<0.001$; Fig. 10 ).

In addition to the five variables evaluated in the meta-analysis, Three secondary outcomes such as Hollander Wound Evaluation Score (HWES), Visual Analogue Score (VAS) and Patient and Observer Scar Assessment Scale data (POSAS) were comparatively assessed in the systematic review part of our study. Sufficient data were not available to conduct a meta-analysis on these variables.

Two studies $(18,20)$, reported on HWES comprising a total of 234 THAs. they reported insignificant higher score with the sutures group (P $=0.30)$. Glennie et al. (21), reported no significant difference between the two cohorts in POSAS scores at 6 weeks or 3 months $(\mathrm{P}=0.71$ and $\mathrm{P}=0.84)$ respectively. The POSAS includes a 6-item observer rating scale and a 6 -item patient rating scale. Each item is rated from 1 to 10 where a score of 1 is given when the scar characteristic is closest to 'normal' skin and a score of 10 reflects the worst imaginable scar for a best possible score of 6 and a worst possible score of 60 points (22). VAS pain scores were similar for both groups at 6 weeks and 3 months, $(\mathrm{P}=0.72$ and 0.83$)$ respectively $(21)$.

\section{DISCUSSION}

Currently the health care system advocates the delivery of high-quality care with reducing the expenditures. Consequently, Orthopaedic surgeons have established incorporated care routes intended for restructuring episodes of care with the purpose of boosting the value equation (Value = Quality/ Cost). Recently, surgeons have improved the value equation by focusing their efforts at fields associated with substantial cost including implant negotiations, LOS, and postoperative rehabilitation (23). However, as the healthcare pathways become efficient, orthopaedic surgeons have shifted their interest to the lighter elements of Total Joint Arthroplasty(TJA). One of these elements was been overlooked is skin closure after TJA. Noteworthy, it is the only part of the procedure that is visible to the patient and hugely affects patient satisfaction. Additionally, any complications associated with THA's wounds have been accountable for major 
expenses including prolonged LOS, readmissions, and more revision procedures (24). In light of the currentconcept of value-based care, and the gathering evidence bordering the expensive complications of unsuccessful wound healing, this meta-analysis and systematic review was conducted to provide a guide to the optimum skin closure technique after primary THA. There are several meta-analyses assessing the postoperative wound complications associated with skin closure techniques after TJA. Kim et al (5), comparatively evaluated skin closure after Total Knee Arthroplasty (TKA) . Other authors evaluated the incidence of wound complications with the use of barbed and traditional sutures for skin closure in TKA. They focused on the fascial and subcutaneous layers after TKA but they did not specifically explored skin closure in their meta-analysis $(25,26)$.

Another author conducted a systematic review and meta-analysis comparing sutures to staples for skin closure after trauma and orthopaedic surgeries in general (27). Each region in the body has a unique tissue perfusion, and wound healing characteristics (28). We could not find any metanalyses or systematic review in literatures compared skin complications, resource utilisation and perioperative outcomes between sutures and staples for primary skin closure after THA. Our meta-analysis demonstrated that sutures had insignificant marginal advantages for wound infections, LOS, and wound oozing. On the contrary, staples had less cost and time for closure with higher patient's satisfaction. One meta-analysis about skin closure after trauma and orthopaedic in general did not mentioned any significant difference in superficial infection and secondary outcomes comparing sutures (27). the same conclusion was mentioned by the meta-analysis on TKA (5). Additionally, the researchers reported that sutures may be linked to higher abscess formation and lower rates of prolonged wound discharge after both hip and knee orthopaedic surgeries. Yet, our study differed in that the likelihood of wound infection and oozing was greater with staples. However, in our analysis, no clinical wound complication variables reached statistical significance. Some studies gave a physiological justification for the differences in outcomes associated with various skin closure techniques. The focus was on perfusion studies at the wound site estimating the wound's ability to heal (28). In the absence of ultimate healing parameters, wounds are vulnerable to higher rates of complications including infections (29). Graham et al conducted a comparative spectrographic assessment between the two wound closure techniques, he found the staples (spaced at least 6 $\mathrm{mm}$ apart) and Vicryl (Ethicon, Somerville, NJ) sutures comparably perfused the surrounding tissue by postoperative day 7 . The investigators concluded that an optimal balance between oxygen tension and mechanical integrity of the wound was necessary for ideal healing (30). In contrast, Cody et al (31), measured the blood flow surrounding the wound immediately following closure using laser-assisted indocyanine green angiography and concluded that subcuticular sutures offered better perfusion compared with staples. In fact, the blood flow actually increases substantially between postoperative days three and sevenx (30).which let us take the results of Cody et al with cautions. Future studies inspecting the blood flow at various postoperative times with different skin closure techniques are required for better understanding of the associated clinical and functional implications in the setting of THA.

Despite, the adequate tissue perfusion was the main element in wound associated complications after various wound closure techniques. A histological study in THA patients demonstrated that a direct inflammatory reaction produced by the adjacent tissue to the suture material, which can imitate the signs and symptoms of wound infection. The study examined three patients at three, six, and nine weeks postoperatively who presented with pain, erythema, induration, and local tenderness with or without wound oozing associated with the wounds closed with Vicryl suture. In addition to the high erythrocyte sedimentation rate(ESR) and C-reactive protein(CRP) levels, the intraoperative outcomes of abscess formation extending from the subcutaneous tissue into the joint capsule. Although the initial diagnosis was infections, the culture results were negative for any bacterial growth. Only numerous giant-cell granulomas and large numbers of eosinophils on the pathology report which was consistent with nonimmunologic foreign-body 
reactions. A granulomatous suture reaction was the final diagnosis (32).

Another author injected the wounds (either closed with sutures or staples) with Staphylococcus aureus. The skin incisions that was closed with staples showed lower infection rates, that concluded that sutures may serve as a nidus for infection (33). All these laboratory studies backing the findings presented in our study, and recommending against the use of sutures that may increase the complication rates due to inadequate tissue perfusion, direct tissue inflammation mimicking infection or the creation of a fertile field for infection.

The economic implications associated with wound closure have direct (supply costs) and indirect contributors (wound closure time, operative time, and postoperative complications) associated with wound closure .

Four studies reported the suture cohort took on average 2.54 minutes longer than the staple cohort $(10,18,20,21)$. However, these studies did not calculated other variables that can change the operative time of a procedure, it was difficult to conclude the amount related to each skin closure technique and the surgeon who closed the wound as the time for skin closure varies from one surgeon to others.

Moreover, fully staffed operating room costs $\$ 62$ USD per minute (34). The health care organisations are under pressure to deliver value-based care, the differences in operative time associated with sutures vs staples should be heavily considered when deciding the most cost-effective closure technique after THA (3). A cost analysis study compared the perioperative costs between the two. It concluded that when considering all intraoperative materials and staff costs, the suture cohorts added an extra $\$ 386.80$ USD (35). The researchers also reported an additional \$253.53 USD in cost correlated with the suture cohort in total perioperative expenses which included total intraoperative costs and postoperative hospital costs (35). From the collected data, the overall scores of the two techniques were comparable. Wound cosmesis scores were slightly in favour of the sutures group for both groups based on the Hollander Wound Evaluation Scale score $(18,20)$. However, the VAS scores favoured the staples group
(21). All included studies in our analysis assessed the wound complications after either lateral or posterior approach of the hip, however the direct anterior approach caused a significant bigger number of wound complications (36), that should be taken in consideration as a limitation. Khurana et al (13), claimed that using Dermabond after skin closure by subcuticular sutures without any dressing has a low rate of post-operative wound complication but he didn't do any comparison to skin closure using staples. Another author found a significantly higher incidence of superficial wound infection following surgical treatment for hip fracture when wound closure was performed using metallic staples (11). Of note, his study was on hip trauma not primary THA.

The data used in this study was obtained from several studies estimating various skin closure techniques. These techniques and material were similar, but not identical. An example of this varieties the use of either traditional sutures or barbed sutures for deeper layers of the wound, which were not analysed in our study. Other issues caused the high heterogeneity included a lack of standard definitions for certain complications such as wound oozing and wound infection if it was deep or superficial. Another source of limitation included the inclusion of one retrospective studies in addition to the four RCTs used in the meta-analysis. As with this retrospective study, these types of observational patterns are more susceptible to bias in data collection and are confronted by the incompetence to control for all the variables measured between the different cohorts included in each study.

\section{CONCLUSION}

Our analysis evaluates differences in infection rate, operative time, length of stay time to wound closure, wound oozing, associated costs, and cosmetic assessments for skin closure with either subcuticular sutures or staples techniques after THA. In summary, primary skin closure with sutures had insignificant marginal advantages for wound infections, LOS, and wound oozing. On the contrary, staples had less cost and time for closure with higher patient's satisfaction. The 
use of staples after THA may have several slight clinical advantages over sutures. However, owing to the complexities associated with wound closure, future clinical and laboratory studies assessing their complication outlines must be examined before an optimum technique can be determined.

\section{Contributors}

All authors had made impactful contributions to the manuscript submitted. HE is the primary author of said manuscript. He made substantial contributions to the design of the work, acquisition of data, analysis/interpretation, and writing the manuscript. RG played an integral role in selecting included studies during the screening process. He provided necessary guidance, support and mentorship throughout the whole process. He was involved in study design, statistical analysis and revising intellectual property. SG played an integral role for this study. They provided necessary guidance, support and mentorship throughout the whole process. He was involved in study design, statistical analysis and revising the intellectual property.

\section{REFERENCES}

1. Oleske DM, Bonafede MM, Jick S, Ji M, Hall JA. Annals of Epidemiology Electronic health databases for epidemiological research on joint replacements: considerations when making cross-national comparisons q. Ann Epidemiol [Internet]. 2014 ; 24(9) : 660-5. Available from : http://dx.doi.org/10.1016/j.annepidem.2014.06.003

2. Kurtz S, Ong K, Lau E, Mowat F, Halpern M. Projections of primary and revision hip and knee arthroplasty in the United States from 2005 to 2030. J Bone Joint Surg Am [Internet]. $2007 \mathrm{Apr}$; 89(4) : 780-5. Available from : http:// www.ncbi.nlm.nih.gov/pubmed/17403800

3. David C. Ayers MD, Kevin J. Bozic MD M. Medicare's Bundled Payment Care Initiatives (BPCI) and. Clin. Orthop. Relat. Res. 2013 ; (2013) : 471.

4. John Philip Andrawis MD, MBA KECM, Kevin J. Bozic MD M. Health Policy Im-plications of Outcomes Measurement in Orthopaedics. Clin. Relat. Res. 2013 ; $10.1007 / \mathrm{s} 1$.

5. Kim KY, Anoushiravani AA, Long WJ, Vigdorchik JM, Fernandez-madrid I, Schwarzkopf R. A Meta-Analysis and Systematic Review Evaluating Skin Closure After Total Knee Arthroplasty d What Is the Best Method? J Arthroplasty [Internet]. 2017 ; 32(9) : 2920-7. Available from : http://dx.doi.org/10.1016/j.arth.2017.04.004

6. Al-houraibi RK, Aalirezaie A, Adib F, Anoushiravani A, Bhashyam A, Binlaksar R, et al. General Assembly, Prevention, Wound Management: Proceedings of International Consensus on Orthopedic Infections. 2018.
7. Gililland JM, Anderson LA, Barney JK, Ross HL, Pelt CE, Peters CL. Barbed Versus Standard Sutures for Closure in Total Knee Arthroplasty: A Multicenter Prospective Randomized Trial. J Arthroplasty [Internet]. 2014 Sep; 29(9) : 135-8. Available from : https://linkinghub.elsevier. com/retrieve/pii/S0883540314003532

8. EImallah RK, Khlopas A, Faour M, Chughtai M, Malkani AL, Peter M, et al. Economic evaluation of different suture closure methods: barbed versus traditional interrupted sutures. Ann Transl Med [Internet]. 2017 Dec ; 5(S3) : S26-S26. Available from: http://atm.amegroups. com/article/view/16344/18051

9. Smith TO, Sexton D, Mann C, Donell S. Sutures versus staples for skin closure in orthopaedic surgery: metaanalysis. BMJ [Internet]. 2010 Mar 16; 340 (mar16 1) : c1199-c1199. Available from: http://www.bmj.com/cgi/ doi/10.1136/bmj.c1199

10. Livesey C, Wylde V, Descamps S, Estela CM, Bannister GC, Learmonth ID, et al. Skin closure after total hip replacement: A randomised controlled trial of skin adhesive versus surgical staples. J. Bone Jt Surg. - Ser B. 2009 ; 91(6) : 725-9.

11. Shetty AA, Kumar VS, Morgan-Hough C, Georgeu GA, James KD, Nicholl JE. Comparing wound complication rates following closure of hip wounds with metallic skin staples or subcuticular vicryl suture : a prospective randomised trial. J. Orthop. Surg. (Hong Kong). 2004 ; 12(2) : 191-3.

12. Biancari F, Tiozzo V. Staples versus sutures for closing leg wounds a er vein gra harvesting for coronary artery bypass surgery. (Review). 2010.

13. Hurana AK, Arker SP, Oel VG, Lderman PMA. Dermabond wound closure in primary hip arthroplasty. $2008 ; 74: 349-53$.

14. Julian P.T. Higgins JT, Jacqueline Chandler, Miranda Cumpston TL, Welch MJP and VA. Cochrane Handbook for Systematic Reviews of Interventions. 2019, 241-284 p.

15. Med AJP. Level of evidence provided by US preventive services task force. 2001 ;

16. Hollander JE, Singer AJ, Valentine S, Henry MC. Wound Registry : Development and Validation. Ann Emerg Med [Internet]. 1995 May ;25(5) : 675-84. Available from : https://linkinghub.elsevier.com/retrieve/pii/S01960644 95701834

17. (2014) RM (RevMan) [Computer P, Centre V 5. 3. CTNC, Collaboration. TC. Review Manager V.5.0.

18. Khan RJK, Fick D, Yao F, Tang K, Hurworth M, Nivbrant B, et al. A comparison of three methods of wound closure following arthroplasty. A prospective, randomised, controlled trial. J. Bone Jt. Surg. - Ser B. 2006 ; 88(2) : 23842.

19. Roumeliotis L, Graham NM. Barbed suture and glue in skin closure during lower limb arthroplasty: Reduced delayed discharge due to wound exudate. J. Wound Care. 2019 ; 28(11) : 784-9. 
20. Rui M, Zheng X, Sun SS, Li CY, Zhang XC, Guo KJ, et al. A prospective randomised comparison of 2 skin closure techniques in primary total hip arthroplasty surgery. HIP Int. 2018 ; 28(1) : 101-5.

21. Glennie RA, Korczak A, Naudie DD, Bryant DM, Howard JL. MONOCRYL and DERMABOND vs Staples in Total Hip Arthroplasty Performed Through a Lateral Skin Incision : A Randomized Controlled Trial Using a PatientCentered Assessment Tool. J Arthroplasty [Internet]. 2017 ; 32(8) : 2431-5. Available from : http://dx.doi.org/10.1016/j. arth.2017.02.042

22. van de Kar D. POSAS Observer scale,POSASv2.0. Plast. Reconstr. Surg. 2005 ; 116 : 514-22.

23. Froimson MI, Rana A, White RE, Marshall A, Schutzer SF, Healy WL, et al. Bundled Payments for Care Improvement Initiative : The Next Evolution of Payment Formulations. J Arthroplasty [Internet]. 2013 Sep ; 28(8) : 157-65. Available from: https://linkinghub.elsevier.com/ retrieve/pii/S0883540313005160

24. Whitehouse JD, Friedman ND, Kirkland KB, Richardson WJ, Sexton DJ. The Impact of Surgical-Site Infections Following Orthopedic Surgery at a Community Hospital and a University Hospital Adverse Quality of Life, Excess Length of Stay, and Extra Cost. Infect Control Hosp Epidemiol [Internet]. 2002 Apr 2 ;23(4) : 183-9. Available from : https://www.cambridge.org/core/product/identifier/ S0195941700084708/type/journal_article

25. Meena S, Gangary S, Sharma P, Chowdhury B. Barbed versus standard sutures in total knee arthroplasty : a metaanalysis. Eur J Orthop Surg Traumatol [Internet]. 2015 Aug $15 ; 25(6)$ : 1105-10. Available from : http://link.springer. com/10.1007/s00590-015-1644-z

26. Zhang W, Xue D, Yin H, Xie H, Ma H, Chen E, et al. Barbed versus traditional sutures for wound closure in knee arthroplasty: a systematic review and meta-analysis. Sci Rep [Internet]. 2016 Apr 25 ;6(1) : 19764. Available from : http://www.nature.com/articles/srep19764

27. Krishnan R, Macneil SD, Malvankar-mehta MS. Comparing sutures versus staples for skin closure after orthopaedic surgery : systematic review and meta-analysis. $2016 ; 1-11$.

28. Jonsson K, Jensen JA, Goodson WH, Scheuenstuhl H, West J, Hopf HW, et al. Tissue Oxygenation, Anemia, and Perfusion in Relation to Wound Healing in Surgical Patients. Ann Surg [Internet]. 1991 Nov;214(5) : 605-
13. Available from: http://journals.lww.com/00000658199111000-00011

29. Dennis DA. Wound Complications in Total Knee Arthrplasty. In : Knee Arthroplasty [Internet]. Vienna : Springer Vienna; 2001. p. 163-9. Available from: http://link. springer.com/10.1007/978-3-7091-6185-2_15

30. Graham D., Jeffery J., Bain D, Davies P, Bentley G. Staple vs. subcuticular vicryl skin closure in knee replacement surgery: a spectrophotographic assessment of wound characteristics. Knee [Internet]. 2000 Dec ;7(4) : 239-43. Available from: https://linkinghub.elsevier.com/ retrieve/pii/S0968016000000557

31. Cody C. Wyles BS, Steven R. Jacobson MD, Matthew T. Houdek MD, Dirk R. Larson MS, Michael J. Taunton MD, Franklin H. Sim MD RJSM\& RTTM. CORR Insights ${ }^{\circledR}$ : The Chitranjan Ranawat Award : Running Subcuticular Closure Enables the Most Robust Perfusion After TKA : A Randomized Clinical Trial. Clin Orthop Relat Res [Internet]. 2016 Jan 1 ;474(1) : 57-9. Available from : http://link.springer.com/10.1007/s11999-015-4277-y

32. Sayegh S, Bernard L, Stern R, Pache J-C, Szalay I, Hoffmeyer P. Suture granuloma mimicking infection following total hip arthroplasty. J Bone Jt Surgery-American Vol [Internet]. 2003 Oct;85(10) : 2006-9. Available from : http://journals.lww.com/00004623-200310000-00023

33. Stillman RM. Skin Staples in Potentially Contaminated Wounds. Arch Surg [Internet]. 1984 Jul $1 ; 119(7)$ : 821. Available from: http://archsurg.jamanetwork.com/article. aspx?doi=10.1001/archsurg.1984.01390190061013

34. Shippert RD. A Study of Time-Dependent Operating Room Fees and How to save $\$ 100000$ by Using TimeSaving Products. Am J Cosmet Surg [Internet]. 2005 Mar $30 ; 22(1)$ : 25-34. Available from : http://journals.sagepub. com/doi/10.1177/074880680502200104

35. Eggers MD, Fang L, Lionberger DR. A Comparison of Wound Closure Techniques for Total Knee Arthroplasty. $J$ Arthroplasty [Internet]. $2011 ; 26(8)$ : 1251-1258.e4. Available from: http://dx.doi.org/10.1016/j.arth.2011.02. 029

36. Christensen CP, Karthikeyan T, Jacobs CA. Greater Prevalence of Wound Complications Requiring Reoperation With Direct Anterior Approach Total Hip Arthroplasty. $J$ Arthroplasty [Internet]. 2014 Sep ;29(9) : 1839-41. Available from: https://linkinghub.elsevier.com/retrieve/ pii/S0883540314002940 